\title{
Effects of Particulate Matter on Healthy Skin: A Comparative Study Between High and Low- particulate Matter Periods
}

Se Jin Oh

Samsung Medical Center https://orcid.org/0000-0001-7525-4740

Dokyoung Yoon

Samsung Medical Center

Ji-Hye Park

Samsung Medical Center

Jong Hee Lee ( $\nabla$ bell711@hanmail.net)

https://orcid.org/0000-0001-8536-1179

Keywords:

Posted Date: July 15th, 2020

DOI: https://doi.org/10.21203/rs.3.rs-41713/v1

License: (c) (1) This work is licensed under a Creative Commons Attribution 4.0 International License.

Read Full License 


\section{Abstract}

The authors have requested that this preprint be removed from Research Square. 